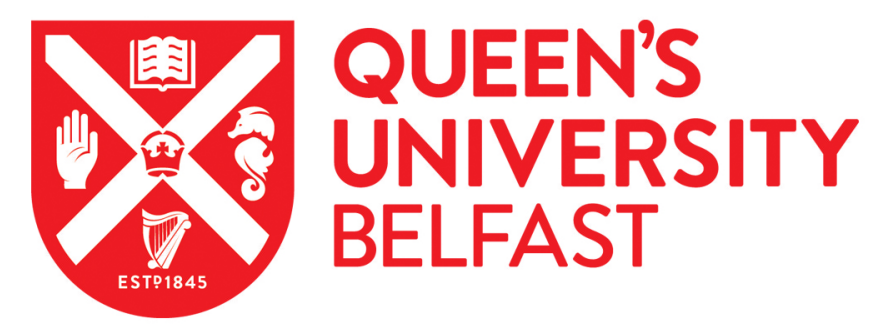

\title{
The effectiveness of smart phone apps in improving financial capability
}

French, D., McKillop, D., \& Stewart, E. (2020). The effectiveness of smart phone apps in improving financial capability. European Journal of Finance, 26(4-5), 302-318. https://doi.org/10.1080/1351847X.2019.1639526

\author{
Published in: \\ European Journal of Finance
}

Document Version:

Peer reviewed version

Queen's University Belfast - Research Portal:

Link to publication record in Queen's University Belfast Research Portal

Publisher rights

Copyright 2019, Taylor \& Francis.

This work is made available online in accordance with the publisher's policies. Please refer to any applicable terms of use of the publisher.

\section{General rights}

Copyright for the publications made accessible via the Queen's University Belfast Research Portal is retained by the author(s) and / or other copyright owners and it is a condition of accessing these publications that users recognise and abide by the legal requirements associated with these rights.

Take down policy

The Research Portal is Queen's institutional repository that provides access to Queen's research output. Every effort has been made to ensure that content in the Research Portal does not infringe any person's rights, or applicable UK laws. If you discover content in the Research Portal that you believe breaches copyright or violates any law, please contact openaccess@qub.ac.uk. 


\title{
Title: The effectiveness of smart phone apps in improving financial capability
}

\author{
Authors: Declan French ${ }^{1}$, Donal McKillop* and Elaine Stewart ${ }^{2}$
}

\begin{abstract}
This study is the first to assess whether smartphone apps can be utilised to improve financially capable behaviours. In this study four smartphone apps, packaged together under the title 'Money Matters', were provided to working age members (16-65 years) of the largest credit union in Northern Ireland (Derry Credit Union). The smartphone apps consisted of a loan interest comparison app, an expenditure comparison app, a cash calendar app, and a debt management app. The assessment methodology used was a Randomised Control Trial (RCT) with the UK Financial Capability Outcome Frameworks used to set the context for the assessment. For those receiving the apps (the treatment group) statistically significant improvements were found in a number of measures designed to gauge 'financial knowledge, understanding and basic skills' and 'attitudes and motivations'. These improvements translated into better financially capable behaviours; those receiving the apps were more likely to keep track of their income and expenditure and proved to be more resilient when faced with a financial shock.
\end{abstract}

Keywords: Digital literacy; smartphone apps; financially capable behaviours; randomised control trial; credit unions

\section{JEL classification: D12 D14}

Funding: This work was supported by Economic and Social Research Council [Development of webbased tools to enhance the financial capability of credit union members; Money Advice Service [What Works Fund] [Financial Capability Tools: Assessment Framework].

\footnotetext{
${ }^{1}$ Dr Declan French, Queen's Management School, Queen's University Belfast, e-mail: declan.french@qub.ac.uk 2 Dr Elaine Stewart, Queen's Management School, Queen's University Belfast, e-mail: e.stewart@qub.ac.uk *Address for correspondence: Professor Donal McKillop, Queen's University Belfast, Queen's Management School, Riddel Hall,185 Stranmillis Road, Belfast BT9 5EE, UK e-mail: dg.mckillop@qub.ac.uk
} 


\section{Introduction}

Making good financial decisions is important for a person's economic and financial well-being (Money Advice Service, 2013). Whether a person is in a position to make good financial decisions is, however, dependent upon their financial capability. The OECD defines financial capability as "a combination of awareness, knowledge, skill, attitude and behaviour necessary to make sound financial decisions and ultimately achieve individual financial wellbeing'"' (OECD INFE, 2011). This emphasises that financial capability is about not only having knowledge, understanding and skills but also the ability to apply these attributes in a way that results in positive financial outcomes (Spencer et al., 2015). Financial capability does not necessarily follow from having knowledge, understanding and skills it is shaped also by the psychological motivations and biases that drive our behaviour (Hershfield et al. 2015). ${ }^{1}$

Increasing levels of financial capability in the UK population is a Government priority (Financial Capability Strategy for the UK, 2015). Measurement of the financial capability of the UK population suggests that at best it is mediocre (Spencer et al., 2015). Approximately 30 percent of the UK population do not make a budget. One in six have problems in identifying the balance on their bank statement. Almost 90 percent of UK adults do not read the full terms and conditions when taking out financial products and nearly half of UK adults admit falling into debt as a direct result of their social lives. (Money Advice Service, 2013). A survey undertaken by the Financial Services Authority (FSA) in 2005 found that those who scored well below average on all aspects of financial capability were young (average age 36), and included roughly equal numbers of single people and couples. Furthermore, their incomes and levels of product holding were lower than average, but not the lowest of all the groups surveyed (FSA, 2006). ${ }^{2}$

The Financial Capability Strategy for the UK, 2015 highlights the improvement of digital literacy as an important outcome in the advancement of financially capable behaviours ".... being able to use online banking services, to use mobile apps, and to compare financial services online is

\footnotetext{
${ }^{1}$ These psychological motivations and biases include, non-impulsiveness (Birkenmaier et al., 2013), optimism (Puri and Robinson, 2007, Kahneman, 2011, Kenrick et al., 2013), confidence (Parker et al., 2012, Fernandes et al., 2014, Letkiewicz et al, 2016) and peer influences (Chitegi and Stafford, 1999, Hong et al. 2004, Kempson et al., 2006).

2 The FSA (2006) noted that there is no single indicator of financial capability; rather it encompasses four domains - 'managing money', 'planning ahead', 'choosing products' and 'staying informed'.
} 
crucial for being able to keep track of your money and make informed decisions." (Bagwell et al., 2014, p22, Financial Capability Outcome Frameworks). Digital literacy is the ability to effectively and critically locate, evaluate and create information using a range of digital technologies (Spires and Bartlett, 2012). There are five basic digital skills: managing information, communicating, problem solving, transacting and creating (Reedy and Goodfellow, 2012). Attainment of these digital skills could save the average person in the UK £744 per annum (Lloyds Bank, 2017). However, 1 in 10 UK adults (aged 16+) have never used the internet (ONS, Labour Force Survey 2017), and 4.3 million people are thought to have none of the five basic digital skills (Lloyds Bank, 2018).

In the UK, 41 million 16-75 year olds own a smart phone, with those aged 55-75 the fastest growing adopters (Deloitte, 2017). While there is extensive research on the effectiveness of smartphone apps in the improvement of health outcomes and behaviours, there are no studies investigating the efficacy of smartphone apps as a means of improving financial capability. ${ }^{3}$ Our study addresses this paucity of research by assessing whether four smartphone apps, packaged together under the title Money Matters, could improve financially capable behaviours of working age members (16-65 years) of the largest credit union in Northern Ireland (Derry Credit Union). ${ }^{4}$ The smartphone apps consisted of a loan interest comparison app (Money Costs), an expenditure comparison app (Spend NI), a cash calendar app (Cash Calendar), and a debt management app (Snowball).

We used a Randomised Control Trial (RCT) to assess the efficacy of the smartphone apps. The analysis was conducted based on intention to treat (ITT) where outcomes are compared between those receiving the smartphone apps (treatment group) and those not receiving the apps (control group). However, often in RCTs subjects do not comply with the treatment and in the case of high non-compliance, the intervention may be ineffective but may still be efficacious for those who adhere to the treatment. To accommodate for imperfect adherence we use the 'complier average casual effect' (CACE), developed by Imbens and Rubin (1997),

\footnotetext{
${ }^{3}$ A majority of this research has focused on primary outcomes (any objective measure of health or health service delivery) with assessment of the effectiveness of smartphone apps on secondary (self-reported) outcomes less prevalent, (Ali et al., 2016, Haskins et al., 2017).

${ }^{4}$ The development cost of the smartphone apps was $£ 50,000$. Funding support for the development and testing of the apps was provided by the ESRC and the Money Advice Service (What Works Fund).
} 
and report results where outcomes are compared between compliers in the treatment group and those who would have complied in the control group.

The UK Financial Capability Outcome Frameworks provides the context for the RCT. The evaluation initially assessed whether access to the smartphone apps, improved financial knowledge, understanding and basic skills (i.e., loan confidence, financial literacy and digital literacy) as well as attitudes and motivations (i.e. the ability to effect change, resilience in the face of stressful events, spending behaviour and planning for the future). The evaluation then considered whether changes in ability and mindset translated into better financially capable behaviours (i.e., management of bills, keeping track of finances, maximising income and building financial resilience through regular saving). The assessment concluded by considering whether changes in behaviour resulted in improved financial wellbeing (i.e., keeping up with bills and credit commitments, improvements in financial planning, improved food security).

A number of insights emerged from the investigation. First, those receiving the smartphone apps experienced improvements in financial knowledge, understanding and basic skills. They expressed greater confidence in their understanding of loan repayments and demonstrated improved financial literacy. Secondly, receiving the smartphone apps led to changes in attitudes and motivations. Those provided with the apps were less likely to prefer to live for today, reported a greater sense of self-efficacy and a greater confidence in their ability to improve financial decision-making through engaging with technology. Thirdly, the identified changes in financial knowledge, understanding and basic skills, and attitudes and motivations translated into better financially capable behaviours. Those receiving the smartphone apps proved more resilient when subject to a financial shock and were more likely to keep track of their income and expenditure. Unfortunately, the improvements in financially capable behaviours did not result in improved financial wellbeing. Arguably, this was due to the RCT being conducted over a six-month period; too short a period for improvements in financial wellbeing to emerge.

This study is the first to demonstrate that digital technology, in the form of smartphone apps, can be utilised to improve financially capable behaviours. Four out of five UK adults now have a smartphone. It is therefore reasonable to suggest that our study has demonstrated an 
accessible and cost-effective means for the targeting of interventions to improve the financial capability of a significant proportion of the UK population. The remainder of the study is organised as follows. Section 2 provides a review of the literature, the methodological approach is detailed in section 3 and the data described in section 4 . The empirical findings are presented in section 5 with concluding comments reported in section 6 .

\section{Literature Review}

In this section of the paper, we commence by drawing on the literature to define financial capability and distinguish between it and financial literacy. The discussion then considers literature pertaining to financial knowledge, understanding and basic financial skills, which arguably are the foundation stones upon which financially capable behaviours are built. Attitudes and motivations shape financially capable behaviours and we consider the importance of potential influences such as impulsiveness, optimism, confidence, resilience and susceptibility to peer effects. The overview concludes with consideration of the relationship between digitalisation and financial capability.

\subsection{Financial Capability}

Being financially literate is a necessary although not sufficient condition for the achievement of financial capability (Lusardi, 2011). Financial literacy reflects how much knowledge one has about various financial matters, whereas financial capability is the ability to apply that knowledge in a meaningful way resulting in positive financial outcomes, (Spencer et al., 2015). ${ }^{5}$ Someone can be financially literate (in the sense that they have the knowledge, understanding and skills which would enable them to manage their personal finances well) without necessarily being financially capable, as demonstrated by their actual behaviour, (Mundy 2011). Financial capability is determined in part by the psychological motivations and biases that drive our behaviour (Hershfield et al., 2015). These behavioural hurdles are not necessarily character flaws; they are in many instances natural aspects of human behaviour, holding us back from

\footnotetext{
${ }^{5}$ Taylor (2011) provides a slightly more nuanced definition, referring to financial capability as the combination of knowledge, attitudes, and behaviours that enable a person to navigate successfully their economic life.
} 
optimally managing our finances. (Spencer et al., 2015). The OECD defines financial capability as 'a combination of awareness, knowledge, skill, attitude and behaviour necessary to make sound financial decisions and ultimately achieve individual financial wellbeing' (OECD INFE, 2011). In this context, 'knowledge' is the ability to understand personal and broader financial matters, 'skill' is the ability to apply that knowledge in everyday life, and 'attitude and behaviour' refers to having the self-confidence to make appropriate financial decisions (French and McKillop, 2016).

Financially capable behaviour does not yet have a standard scale of measurement, (Shephard et al., 2017). Rather, a range of measures are used to capture the behaviours that people exhibit or the actions they take, for example saving regularly, keeping track of their finances, working towards longer-term goals, or how they use credit (Atkinson, 2016, Money Advice Service, 2016).

\subsection{Financial Knowledge, Understanding and Basic Skills}

Financial knowledge, understanding and basic financial skills, which many categorise as financial literacy (Lusardi and Mitchell, 2007) are the foundation stones upon which financially capable behaviours are built. A significant body of research has established that those who are more financially literate have better economic outcomes. Poor understanding of interest rate calculations is associated with higher debt burdens, incurring greater fees, and defaults and delinquency (Campbell, 2006, Bucks and Pence, 2008, Gerardi et al., 2010, Disney and Gathergood, 2013, Duca and Kumar, 2014). Poor money management skills are a strong negative predictor of the tendency to overspend and to worry about financial affairs (Garđarsdóttir and Dittmar, 2012). Financial literacy is positively correlated with planning for retirement, savings and wealth accumulation (Hastings and Mitchell, 2011, Van Rooij, et al., 2012). Financial literacy is predictive of investment behaviours including stock market participation (Van Rooij et al., 2011, Almenberg and Dreber, 2011, Arrondel et al., 2012) and choosing a low fee investment portfolio (Choi et al., 2009).

Research has mainly used performance test questions to measure the various components of financial literacy (Lusardi and Mitchell 2007, 2011, Van Rooij et al., 2011, 2012). These 
questions capture knowledge and understanding of elements considered important in making savings and investment decisions. This includes the capacity to do interest rate calculations, an understanding of inflation and an understanding of portfolio diversification. About one-third of studies also use self-assessment procedures in conjunction with performance tests questions to measure financial literacy (Hastings and Mitchell, 2011). The literature finds that self-assessed financial capabilities and performance test based measures are positively correlated (Lusardi and Mitchell, 2014).

\subsection{Attitudes and Motivations}

Attitudes, motivations and biases shape financial capability behaviours (Shephard et al., 2017). The authors found that in the Netherlands psychological motivations and biases explained twice the variance in financial capability behaviour compared to the explanatory power of financial knowledge and spending attitudes alone. The important psychological constructs influencing financial capability behaviour were those of non-impulsiveness, optimism, confidence, goal orientation, and susceptibility to peer influences.

Those who are non-impulsive are better financial decision makers than those who are not because they are able to delay gratification to benefit their overall financial well-being (Birkenmaier et al., 2013). Seeking instant gratification (present bias) over a larger potential reward in the future can result in impulse spending and undermine long-term planning and savings (Von Stumm et al., 2013).

In general, people tend to be optimistic about the future and overconfident about their abilities (Kenrick et al., 2013). Mild optimism correlates with a range of good financial behaviours, such as timely repayment of credit card balance and saving more (Puri and Robinson, 2007). Another benefit of mild optimism is that it supports emotional resilience, which may be important in recovering from negative financial surprises (Kenrick et al., 2013, Kahneman, 2011). Those who are very optimistic, however, are found to have a shorter planning time horizon, are less likely to think that saving is a good thing and, on average, save less than people who are less optimistic (Puri and Robinson, 2007). 
Having confidence in your ability to manage your financial situation is key to improving financial well-being (Fernandes et al., 2014, Parker et al., 2012, Letkiewicz et al., 2016). Those with a high sense of financial self-efficacy (confidence that one can effectively manage one's financial affairs) are considered to be less likely to perceive themselves being at risk for disrupted income, unforeseen expenses, and unsuccessful investments, (Engelberg, 2007). Overconfidence is, however, detrimental. When overconfidence is present, households may fail to seek financial advice, fail to save for retirement, or fail to insure themselves against the potential of loss (Campbell, 2006, Lusardi and Mitchell, 2007).

Susceptibility to peer influences may be either harmful or helpful to financial capability. If peer effects encourage excessive spending, it may limit the ability to maintain a budget. On the other hand, peer influences can encourage people to display positive financial behaviours such as taking out insurance or saving for their retirement (Spencer et al., 2015). People are more likely to invest in the stock market if their family do (Chitegi and Stafford, 1999, Hong et al., 2004), or make a particular investment if other investors do (Bursztyn et al., 2014). Low-income children who receive encouragement and hands-on support from parents are more likely to save (Kempson et al., 2006).

\subsection{Digitalisation and Financial Capability}

Digital literacy is 'the ability to effectively and critically locate, evaluate and create information using a range of digital technologies' (Bagwell et al., 2014, p.22, Financial Capability Outcome Frameworks). The improvement of digital literacy is an important outcome in the advancement of financially capable behaviours, 'budgeting and spending meters and financial goal trackers' can be used to enhance money management skills and control finances while 'interactive online/mobile games' can be used to improve personal financial confidence, (OECD INFE, 2018, p 20). Digital technologies can also be used to nudge consumers into action through 'automated reminders to save or pay back a loan' and to enhance opportunities for financial behaviour changes 'through virtual price/product/offer comparison and just-in time reminders at the point of sale or immediately after' (OECD INFE, 2018, p 22). 
In the UK, 41 million 16-75 year olds own a smart phone, with those aged 55-75 the fastest growing adopters (Deloitte, 2017). Over 22 million adults in the UK regularly used mobile banking apps to access their accounts, (UK Finance, 2018). There is also evidence of an increase in the use of budgeting and saving mobile apps, (Lloyds, 2017). While there is extensive research on the effectiveness of smartphone apps in the improvement of health outcomes and behaviours there are no studies investigating the efficacy of smartphone apps as a means of improving financial capability behaviours. ${ }^{6} 7$ However, two studies assess the effect of alternative forms of digitalisation on financial capability. Servon and Kaestner (2008), assessed whether access to an online financial demonstration program, combined with financial literacy training could help low- and moderate-income individuals be more effective financial actors. A small number of qualitative improvements were identified. Piercy (2018) evaluated the efficacy of online assisted digital transactions (in the form of online training centres) as a way of improving financial capabilities. Digital assistance helped increase the confidence of individuals about their financial future through the building of financial skills.

\section{Methodology}

The standard approach in a randomised control trial (RCT) is to analyse on the basis of intention to treat (ITT) where outcomes are compared between the treatment and control groups. The ITT effect can be determined by a simple OLS regression

$$
Y_{j}=\beta_{0}+\beta_{1} Z_{j}+\varepsilon_{j}
$$

where $Z_{j}$ is an indicator variable for whether subject $j$ has been assigned to the treatment $\left(Z_{j}=1\right)$ or $\operatorname{not}\left(Z_{j}=0\right)$.

\footnotetext{
${ }^{6}$ Currently there are in excess of 260,000 health apps on the market (Peiris et al., 2018).

7 Smartphone app interventions have been demonstrated to be effective in promoting physical activity, weight management, the reduction of alcohol consumption and in the management of diabetes, depression and asthma, (Watts et al., 2013; Glynn et al., 2014; Smith et al., 2014; Chan et al., 2018). Smartphones are more appealing than other intervention methods such as websites, face-to-face counselling and group sessions because apps have the facility to provide information and advice, real-time self-monitoring, feedback, reinforcement, social support, and rewards 'on the go', (Schoeppe et al., 2016). Features that increase app usage include, ease of use, not having too many features, being developed by credential experts, enabling self-monitoring, providing advice on how to change behaviour, including positively framed alerts/reminders/push notifications (but not too frequent), providing accurate tracking functions and incorporating adequate privacy, (O'Reilly et al., 2013; Peng et al., 2016).
} 
But often in trials subjects do not comply with the treatment - either they do not take the treatment or they may take it partially. In the event of high non-compliance, the intervention will probably be ineffective but may still be efficacious for those who adhere to the treatment.

Figure 3.1 Compliance status

\section{Randomized to Treatment $(\mathrm{Z}=1)$}

\begin{tabular}{|l|l|}
\hline Treatment & Treatment not \\
taken $(T=1)$ & taken $(T=0)$ \\
Always-takers & Never-takers \\
or & or \\
Compliers & defiers \\
\hline
\end{tabular}

Randomized to Control $(\mathrm{Z}=0)$

\begin{tabular}{|l|l|}
\hline Treatment & Treatment not \\
taken $(\mathrm{T}=1)$ & taken $(\mathrm{T}=0)$ \\
Always-takers & Never-takers \\
or & or \\
defiers & compliers \\
\hline
\end{tabular}

To deal with imperfect adherence, Imbens and Rubin (1997) developed the 'complier average casual effect' (CACE) where outcomes are compared between compliers in the treatment group and those who would have complied in the control group. They classified subjects into four categories of compliance. 'Compliers' will follow the treatment assignment and take the treatment if randomized to treatment or not take the treatment if randomized to the control group. 'Always-takers' (A) will always receive the treatment regardless of assignment. 'Nevertakers' (N) will refuse the treatment regardless of assignment. 'Defiers' (D) will do the opposite of the randomization assignment. Possible outcomes for these categories are summarized in Figure 3.1.

Assuming outcomes for any subject are unaffected by other subjects' assignment ${ }^{8}$, the ITT effect can be decomposed:

$$
I T T=\bar{Y}_{1}-\bar{Y}_{0}=\left(\bar{Y}_{1 c}-\bar{Y}_{0 c}\right) \pi_{c}+\left(\bar{Y}_{1 A}-\bar{Y}_{0 A}\right) \pi_{A}+\left(\bar{Y}_{1 N}-\bar{Y}_{0 N}\right) \pi_{N}+\left(\bar{Y}_{1 D}-\bar{Y}_{0 D}\right) \pi_{D}
$$

where $\bar{Y}_{1 i}\left(\bar{Y}_{0 i}\right)$ is the mean outcome among those in category $\mathrm{i}$ in the treatment (control) group.

\footnotetext{
8 The stable unit treatment value assumption (SUTVA).
} 
As the apps were password-protected, we expect the number of always-takers to be minimal. Never-takers are assumed to have the same outcomes regardless of assignment (exclusion restriction) and it is conventional to assume also that there are no defiers in the trial (monotonicity assumption). The ITT effect then reduces to

$$
I T T=\left(\bar{Y}_{1 c}-\bar{Y}_{0 c}\right) \pi_{c}
$$

or

$$
C A C E=\bar{Y}_{1 c}-\bar{Y}_{0 c}=\frac{I T T}{\pi_{c}}
$$

This can be estimated using 2SLS with a first-stage regression of actual treatment (T) on treatment assignment $(Z)$ and a second-stage regression of outcome $Y$ on actual treatment $(T)$ since

$$
C A C E=\frac{I T T}{\pi_{c}}=\frac{\bar{Y}_{1}-\bar{Y}_{0}}{\pi_{c}}=\frac{\bar{Y}_{1}-\bar{Y}_{0}}{\bar{T}_{1}-\bar{T}_{0}}=\left(Z^{\prime} T\right)^{-1} Z^{\prime} Y
$$

The CACE estimates are therefore larger than ITT estimates by a factor reflecting the proportion of compliers $\pi_{c}$ in the treatment group and CACE standard errors additionally take account of sampling variability in $\pi_{c}$.

\section{Data}

A market research company carried out pre and post-intervention surveys, June-August 2017 and February-March 2018. From a sampling frame of 835 registered individuals, 500 respondents were interviewed in the pre-intervention survey. Of these, 403 people were surveyed post-intervention (81\%) including 191 (80\%) of those allocated the app (see Table 4.1).

The survey explored participants' financial circumstances, employment, income, attitudes to risk and household demographics. It featured questions from the (MAS) Adult Financial Capability Framework (Financial Capability Strategy for the UK, 2015) and elements from previous work conducted with Northern Irish Credit Unions (French and McKillop, 2016). 


\section{Results}

Table 5.1 below confirms that those in the treatment and control groups interviewed in the post-intervention survey are statistically the same for known factors associated with financial capability. The means for each variable are reported with a statistical test for differences. For every variable, the $p$-values are well above the conventional $5 \%$ or $10 \%$ levels of significance.

\subsection{Usage}

Figure 5.1 profiles the number of times the treatment group opened each of the applications during the trial. Initially usage is high but declines steadily between June and August 2017. Usage during this period reflects the initial download of the apps which were provided to participants on a rolling basis over the June to August period. Engagement and user retention are two of the most commonly identified problems in mobile application usage. For example Statista found that for 2017, approximately 24 percent of apps downloaded from Google Play were accessed only once during the first six months of ownership. ${ }^{9}$ The Cash Calendar was found to be the most popular application, making up 32 percent of the total usage, followed by Spend NI making up 28 percent with Snowball and Money Costs each making up 20 percent of total usage.

Throughout the RCT, use of the apps was promoted through weekly push notifications where information of various forms was sent to participants in the treatment group. In September 2017, the Project Team undertook a money management skills workshop to showcase the capabilities of the apps. ${ }^{10}$ This reinforcement exercise resulted in a marginal increase in app usage with the increase in engagement probably due to both the promotion of the workshop (via Facebook, emails and push notifications) and the workshop itself.

A money skills competition was run over a two-week period in early December 2017 . The competition took the form of seven problems and required participants to use either the Cash

\footnotetext{
${ }^{9}$ https://www.statista.com/statistics/271628/percentage-of-apps-used-once-in-the-us/

10 "A recurring insight from research on behavioural finance is that simple interventions that account for or remove psychological constraints, such as social nudges and reminders, can go a long way toward improving financial behaviour." (World Bank, p 119.)
} 
Calendar, Snowball or Money Costs applications to determine answers. The competition was promoted during November (by email and push notifications) with the deadline for submission of answers early December. There is a pronounced increase in the use of the Cash Calendar, Snowball and Money Costs applications during the promotion phase and over the two-week period in December that the competition was open. Usage of the Spending $\mathrm{NI}$ application which was not part of the competition did not experience any increase in use over the same period.

Figure 5.1 also highlights a further increase in app usage in February and March 2018. This coincided with the period over which the follow-up survey was undertaken. It may therefore be the case that the increase in usage was triggered by fresh communications from the Survey Team as they sought to set up suitable interview dates with participants.

Only $86(45 \%)$ used the apps frequently ( 5 or more times during the intervention period). A further 61 (32\%) used the apps infrequently (less than 5 times) while 44 (23\%) either didn't download or didn't use the apps at all. Frequent users were found to have higher levels of education and were less likely to be retired. Age, gender and hours typically spent online did not affect usage.

Those that infrequently used the apps were asked to detail the reasons for using the apps infrequently and also to identify factors which might encourage them to use the apps more frequently. Reasons most commonly identified for infrequency of use were forgetting about the apps (25\%), having a general interest in digital skills but no interest in our apps (13\%), forgetting about what the apps were for (11\%) and losing their phone (11\%). When asked what would encourage greater use of the apps the answer which dominated was if the information provided by the apps was of greater relevance to them (35\%). The second most important factor identified was if they had greater confidence in being able to understand the information retrieved from the apps (21\%). 


\subsection{Empirical Findings}

The core aims of the evaluation are to assess the extent to which the study has changed financial capability as defined in the Financial Capability Outcome Frameworks, 2015. In summary, the evaluation sought to determine whether the smartphone apps:

i. Improved financial knowledge, understanding and basic skills;

ii. Changed attitudes and motivations;

iii. Whether changes in ability and mindset translated into better financially capable behaviours;

iv. Whether changes in behaviour led to improved financial wellbeing.

For the purposes of the analysis, most variables have been recoded and dichotomised so that high values correspond to the most financially capable result for all variables. For example, the Money Over question asked 'How often would you say you have money over at the end of the week, or end of the month if you budget by month?' on a scale of 1 to 6 where $1=$ Always and $6=$ Never. In the analysis, this variable has been reordered so that $0=\left\{{ }^{\prime} 1\right.$. Always', '2. Most weeks/months', '3. More often than not' $\}$ and $1=\{$ '4. Sometimes', '5. Hardly ever', '6. Never' $\}$. This way a positive coefficient always equates to a 'positive' result. Variables with response scales of 0 to 10 have not been dichotomised.

The study group is not large enough for analysis by each app separately hence our findings show all outcomes for the apps as a package.

\subsubsection{Financial Knowledge, Understanding and Basic Skills}

In our first set of results, we examine the impact of using the apps on financial knowledge, understanding and basic skills (Table 5.2). Our first variable is a measure of understanding of the amount to be prepaid on a financial product such as a loan or credit card. This skill is associated with lower use of high-cost borrowing, lower debt and higher savings (Lusardi and Tufano, 2015). As one of the apps was specifically designed to assist the understanding of the relative cost of borrowing we would expect a degree of increased understanding among those receiving the apps. The proportion of subjects in the treatment group expressing confidence in their understanding of loan repayments is almost ten percent higher $(I T T=0.095)$ than in 
the control group. The CACE estimates indicate that the difference in proportions confident about loan repayments between the control group and those utilising the apps five or more times during the trial is larger again at 17.2 percent. Both results are statistically significant at the 5 percent level.

We measured financial literacy using a series of four simple questions on interpreting a bank statement, numeracy, understanding of inflation and risk diversification. ${ }^{11}$ Financial literacy is associated with higher savings, stock market participation and retirement wealth (Lusardi and Mitchell, 2007; Van Rooij et al., 2011). The proportion of the treatment group answering three or more of these questions correctly is eleven percent higher than in the control group and almost twenty percent higher among those using the apps. The apps are designed to assist in more complex financial decision-making than captured by these financial literacy questions but their use has perhaps led to a greater confidence in the user's more general numeracy and problem-solving abilities.

The remaining questions in this set examine the subject's digital literacy. The ability to use online services such as internet banking and comparison sites in financial transactions was identified as being important for financial capability in the UK Financial Capability Outcome Frameworks (Bagwell et al., 2014). We find no evidence that using the apps led to higher selfrated ability to use the internet for commercial transactions or led to higher reports of improvements in these abilities over the duration of the trial. This is disappointing since two of the questions (Online comparisons and Online comparisons improved) specifically refer to using the internet for comparing financial products and services as in the Money Costs app.

\footnotetext{
${ }^{11}$ The first question asked how much money was in the account of the sample Derry Credit Union statement at the end of the month. The remaining three questions were taken from Lusardi and Mitchell (2011) and have been used in many international surveys. (Question 2) Suppose you had $£ 100$ in a savings account and the interest rate was 2 percent per year. After 5 years, how much do you think you would have in the account if you left the money to grow? (1. More than $£ 102$ 2. Exactly $£ 102$ 3. Less than $£ 1024$. Do not know). (Question 3) Imagine that the interest rate on your savings account was 1 percent per year and inflation was 2 percent per year. After 1 year, would you be able to buy: 1 . More than today 2. Exactly the same as today 3. Less than today 4. Do not know. (Question 4) Do you think that the following statement is true or false? 'Buying a single company stock usually provides a safer return than a stock mutual fund.'
} 


\subsubsection{Attitudes and Motivations}

In this section, we examine the fundamental economic preferences that underlie financial decision-making such as time discounting and consumption influences. Results are presented in Table 5.3.

The first measure is a hypothetical choice between $£ 200$ now and $£ 400$ in two months' time (AER 6400 percent) where the 'correct' answer is to wait. The following six measures also capture aspects of time discounting and attitudes to the future. The proportion of the treatment group stating they do not prefer to live for today is 10.6 percentage points higher than in the control group while for those actually using the apps the difference is 19.3 percentage points. We also see that receiving the smartphone apps is strongly associated with what at first glance seems like a counterintuitive reduction in hatred of borrowing (ITT = $-0.103 ; C A C E=-0.188)$. result. However, we should not be surprised if smartphone apps which have been designed to aid borrowing comparisons and which have been shown above to improve confidence about loans also reduce antipathy towards borrowing. There is no statistically significant difference on the other indicators.

The next four measures capture the individual's confidence in their ability to determine their financial situation. Confidence is associated with better financial planning, budgeting and saving (Neymotin, 2010) and a sense of control is an important determinant for seeking professional financial planning help (Letkiewicz et al., 2016). The proportion of the treatment group reporting a sense of self-efficacy is 8.6 percentage points higher than in the control group $(C A C E=0.156)$. Those receiving the apps are also more likely to report that it is important to keep track of income and expenditure $(I T T=0.041 ; C A C E=0.074)$. The next two measures also capture the individual's ability to effect change by proactively seeking advice or engaging with technology to improve decision-making. The treatment group are no more likely to seek advice from family, friends or a money advice service but they are considerably more willing to use technology for day-to-day financial decisions (ITT = $0.111 ; C A C E=0.201)$. 
There are no significant effects of using the apps for the remaining indicators reflecting the degree to which individuals are influenced by others in their consumption and their degree of resilience to shocks.

\subsubsection{Financially Capable Behaviours}

An individual's financial behaviour is determined by their financial knowledge, understanding and basic skills as well as their attitudes and motivations. We have seen in the previous two subsections that the apps improved ability and mindset to an extent and in this subsection we examine whether these effects translated into better financially capable behaviours. Results are presented in Table 5.4.

The first indicator elicits the individual's likely actions in the event of an unexpected bill of $£ 300$ to be paid in seven days' time where the financially capable response is relying on own resources (savings or reducing consumption) and not resorting to credit (loan, credit card, overdraft or borrowing from family and friends) or selling assets. Lusardi et al. (2011) found widespread fragility to financial shocks in the US and these households were more likely to cut back on essential spending such as healthcare. The treatment group are seen to be more resilient being more likely to report they would rely on their own resources to deal with an unexpected bill $(I T T=0.121 ; C A C E=0.221)$.

The next five measures cover behaviours to track income and expenditure. The treatment group were more likely to regularly check their current account $($ ITT $=0.062 ; C A C E=$ 0.113 ) but this effect is only statistically significant at the 10 percent level. On all other measures there is no effect of using the apps.

There was no effect on the remaining indicators relating to shopping round to maximize income as well as saving regularly. The latter result is surprising given that the treatment group appears more resilient to financial shocks. 


\subsubsection{Financial Wellbeing}

Financial wellbeing reflects the overall financial position of the household. Financially capable behaviour should lead to greater financial wellbeing but is obviously limited by the resources available to the household as well as unanticipated shocks. Results for a number of mainly subjective measures of financial wellbeing including debt levels, arrears, ability to make ends meet and satisfaction with their financial situation are given in Table 5.5. There is no evidence that the apps have improved the household financial situation on any of these measures. We can only speculate as to how improvements in ability and mindset have not led to an improvement in financial wellbeing. The window of the trial could have been too short to see better financial decisions translating into meaningful changes in the household financial situation. Also, members of credit unions tend to be from lower income backgrounds and as such have limited means and are more susceptible to economic shocks. Improvements in financial capability can do little to alter the types of work available to the household to generate income or their vulnerability to ill health, crime and unemployment.

\subsubsection{Improving the technology}

Participants in the treatment group were asked to assess the quality of the apps. In general, the quality of the apps was viewed positively with on average 59 percent of those that downloaded the apps considering them as either very good or good. The Spend NI app was viewed as best (64 percent rated it as either very good or good) while the least popular was the Snowball app (50 percent rated it as either very good or good). Only a small percentage of participants ( 3 to 5 percent) indicated that they did not like the apps.

Participants in the treatment group were then asked to identify what they most liked about each of the apps. Ease of use was the feature that was most liked across all four apps (28 percent on average) followed by content (12 percent) and then functionality ( 8 percent) while speed of use was seldom selected as the most liked feature (3 percent). Participants were also asked to identify what they least liked about each of the apps but more than half reported they did not know. 
A number of questions were asked to assess changes in attitude to digital technology. One quarter of participants receiving the intervention reported that their attitude towards the use of digital technology had changed as a consequence of using the smartphone apps. They suggested that they now think more about how online money advice and guidance could help them; they now see the importance of timing in repayments and interest charges; they see the importance of setting financial goals for the short to medium and longer term; and they recognise the importance of thinking about future financial needs.

\section{Conclusion}

In this study four smartphone apps, packaged together under the title 'Money Matters', were provided to working age members of the largest credit union in Northern Ireland. The apps were designed to enhance financially capable behaviours. An RCT was used to evaluate the apps with the UK Financial Capability Outcome Frameworks providing context for the evaluation.

The assessment of the impact of the apps on financial knowledge, understanding and basic skills revealed that those receiving the apps expressed greater confidence in their understanding of loan repayments with loan confidence most pronounced for those utilising the apps more frequently. Financial literacy also improved and again was strongest for those using the apps more frequently. In the assessment of whether the apps led to changes in attitudes and motivations, it was established that those receiving the apps were less likely to prefer to live for today with this effect greater for those using the apps more frequently. Those receiving the apps also reported a greater sense of self-efficacy and a greater confidence in their ability to improve financial decision-making through engaging with technology.

Importantly, the changes in financial knowledge, understanding and basic skills, and attitudes and motivations, were found to translate into better financially capable behaviours. In particular, those receiving the apps were more resilient when faced with a financial shock in the form of an unexpected bill. They were also more likely to keep track of their income and expenditure through regularly checking their current account. These improvements in financially capable behaviours did not however result in in an improvement in the financial 
situation of the household. This may have been due to fact that the RCT was conducted over a six month period, too short a time frame for improvements in financial wellbeing to emerge.

As part of the study, we also assessed whether changes emerged in attitudes to digital technology. One quarter of those receiving the smartphone apps reported that they now think more about how money advice and guidance could help them. They also reported a better awareness of their future financial needs and of the importance in setting financial goals. They also found use of the apps to have improved their understanding of interest charges and the importance of timing in bill and loan repayments.

There is extensive research documenting the effectiveness of smartphone apps in the improvement of health outcomes and behaviours. Our study is, however, the first to establish the efficacy of smartphone apps as a means of improving financially capable behaviours. As four out of five UK adults now have a smartphone, our study demonstrates that smartphone apps offer money advice providers and related bodies an accessible, cost-effective and credible means for the targeting of interventions to improve the financial capability of their client base. Our study was neither targeted at a particularly segment of the population nor at a particular problem faced by the cohort involved in the trial. The relevance and applicability of a particular app depended on the stage in the financial journey that a trial participant was at and their financial circumstances at that time. Research suggests that the most effective financial programmes are those targeted at a specific audience faced with an explicit area of financial concern, (Martin 2007, Lusardi and Mitchell 2014). The next stage in this research programme will be the targeting of the apps towards a specific cohort and a particular problem for example those from a low-income background struggling with high cost debts. 


\section{References}

Ali, E.E., L. Chew and K.Y. Yap. 2016. 'Evolution and Current Status of Mhealth Research: A Systematic Review' BMJ Innovations 2: 33-40.

Almenberg, J. and A. Dreber. 2011. 'Gender, Stock Market Participation and Financial Literacy' Working Paper Series in Economics and Finance, Stockholm School of Economics.

Arrondel, L., M. Debbich and F. Savignac. 2012. 'Stockholding and Financial Literacy in the French Population' International Journal of Social Sciences and Humanity Studies, 4 (2): 13098063.

Atkinson, A. 2016. OECD/INFE 'International Survey of Adult Financial Literacy Competencies' Edited by O. I. N. O. F. Education. Paris: OECD.

Bagwell, S., C. Hestbaek, E. Harries and A. Kail. 2014. 'Financial Capability Outcomes Framework' www.fincap.org.uk/uk_strategy.

Birkenmaier, J., M. Sherraden and J. Curley. 2013. 'Financial Capability and Asset Development: Research, Education, Policy and Practice' Oxford: Oxford University Press.

Bucks, B. and K. Pence. 2008. 'Do Borrowers Know Their Mortgage Terms?' Journal of Urban Economics, 64: 218-33.

Bursztyn, L., F. Ederer, B. Ferman and N. Yuchtman. 2014. 'Understanding Mechanisms Underlying Peer Effects: Evidence from a Field Experiment on Financial Decisions' Econometrica, 82 (4): 1273-1301.

Campbell, J. 2006. 'Household Finance' Journal of Finance, 61: 1553-1604

Chan, Y., B. Bot, M. Zweig, N. Tignor, W. Ma, C. Suver, R. Cedeno, E. Scott, S. Hershman, E. Schadt and P. Wang. 2018. 'The Asthma Mobile Health Study, Smartphone Data Collected Using Researchkit' Scientific Data 5: 1-11.

Chitegi, N. S. and F. P. Stafford 1999. 'Portfolio Choices of Parents and their Children as Young Adults: Asset Accumulation by African - American Families' American Economic Review, 89 (2): 377-380.

Choi, J.J., D. Laibson and B.C. Madrian. 2009. 'Mental Accounting in Portfolio Choice: Evidence from a Flypaper Effect' American Economic Review, 99 (5): 2085-95.

Deloitte. 2017. 'State of the Smart: Consumer and Business Usage Patterns' http://www.deloitte.co.uk/mobileuk/assets/img/download/global-mobile-consumer-survey2017 uk-cut.pdf 
Disney, R. and J. Gathergood. 2013. 'Financial Literacy and Consumer Credit Portfolios' Journal of Banking and Finance, 37: 2246-2254.

Duca, J.V. and A. Kumar. 2014.' Financial Literacy and Mortgage Equity Withdrawals' Journal of Urban Economics, 80: 62-75

Engelberg, E. 2007. 'The Perception of Self-Efficacy in Coping with Economic Risks among Young Adults: An Application of Psychological Theory and Research' International Journal of Consumer Studies, 31: 95-101

Fernandes, D., J. G., Jr. Lynch and R. G. Netemeyer. 2014. 'Financial Literacy, Financial Education and Downstream Financial Behaviors' Management Science, 60: 1861-1883

Financial Capability Strategy for the UK. 2015. Evidence and Analysis.

Financial Services Authority. 2006. 'Financial Capability in the UK: Establishing a Baseline' London: Financial Services Authority.

French, D, and D.G. McKillop. 2016. 'Financial Literacy and Over Indebtedness in Low-Income Households' International Review of Financial Analysis 48: 1-11

Garđarsdóttir R.B. and H. Dittmar, H. 2012. 'The Relationship of Materialism to Debt and Financial Well-Being: The Case of Iceland's Perceived Prosperity' Journal of Economic Psychology, 33 (3): 471-481.

Gerardi, K., L. Goette, and S. Meier. 2010. 'Financial Literacy and Subprime Mortgage Delinquency: Evidence from a Survey Matched to Administrative Data' Working Paper, Federal Reserve Bank of Atlanta.

Glynn, L.G., P.S. Hayes, M, Casey, F. Glynn, A. Alvarez-Iglesias and J. Newell. 2014. 'Effectiveness of a Smartphone Application to Promote Physical Activity in Primary Care: The SMART MOVE Randomised Controlled Trial'. British Journal of General Practice 64 (624): 384-91.

Haskins, B.L., D. Lesperance, P. Gibbons, and E.D. Boudreaux. 2017. 'A Systematic Review of Smartphone Applications for Smoking Cessation' Society of Behavioural Medicine 7: 292-99.

Hastings, J. and O.S. Mitchell. 2011. 'How Financial Literacy and Impatience Shape Retirement Wealth and Investment Behaviours' Working Paper 16740, National Bureau of Economic Research.

Hershfield, H. E., D. G. Goldstein, W. F. Sharpe, J. Fox, L. Yeykelis, L. L. Carstensen and J. N. Bailenson. 2011. 'Increasing Saving Behavior Through Age-Progressed Renderings of the Future Self' Journal of Marketing Research, 48.SPL, S23-S37.

Hong, H., J. D. Kubik, and J. C. Stein. 2004. Social Interaction and Stock-Market Participation. The Journal of Finance 59 (1): 137-163. 
Imbens, G. W., and D. B. Rubin. 1997. 'Estimating Outcome Distributions for Compliers in Instrumental Variables Models' The Review of Economic Studies 64 (4): 555-574.

Kahneman, D. 2016. 'Thinking, Fast and Slow' New York: Macmillan.

Kempson, E., A. Atkinson, and S. Collard. 2006. 'Saving for Children: A Baseline Survey at the Inception of the Child Trust Fund' HM Revenue and Customs Research Report 18, London: HMRC.

Kenrick, D. T., V. Griskevicius, J. M. Sundie, N. P. Li, Y. J. Li, and S. L. Neuberg. 2013. 'Deep Rationality: The Evolutionary Economics of Decision Making' Social Cognition, 27(5): 764.

Letkiewicz, J., C. Robinson, D. Domian, D. 2016. 'Behavioral and Wealth Considerations for Seeking Professional Financial Planning Help’ Financial Services Review 25 (2): 105-126.

Lloyds Bank 2017 Consumer Digital Index. 2017. https://www.lloydsbank.com/banking-withus/whats-happening/consumer-digital-index.asp

Lloyds Bank 2018 Consumer Digital Index. 2018. https://www.lloydsbank.com/banking-withus/whats-happening/consumer-digital-index.asp

Lusardi, A. 2011. 'Americans' Financial Capability' Working Paper 17103, National Bureau of Economic Research.

Lusardi, A. and O. S. Mitchell. 2007. 'Baby Boomer Retirement Security: The Roles of Planning, Financial Literacy, and Housing Wealth' Journal of Monetary Economics 54 (1): 205-224.

Lusardi, A. and O. S. Mitchell. 2011. 'Financial Literacy and Planning: Implications for Retirement Wellbeing.' In Financial Literacy: Implications for Retirement Security and the Financial Marketplace, Eds. O. S. Mitchell and A. Lusardi. Oxford, Oxford University Press: 1739.

Lusardi, A. and O. S. Mitchell. 2014. 'The Economic Importance of Financial Literacy: Theory and Evidence' Journal of Economic Literature 52 (1): 5-44.

Lusardi, A., D. J. Schneider, and P. Tufano. 2011. 'Financially Fragile Households: Evidence and Implications' Working Paper 17072, National Bureau of Economic Research.

Lusardi, A. and P. Tufano. 2015. 'Debt Literacy, Financial Experiences, and Overindebtedness' Journal of Pension Economics and Finance 14 (4): 332-368.

Martin, M. 2007. 'A Literature Review on the Effectiveness of Financial Education', Working Paper, Federal Reserve Bank of Richmond,

Money Advice Service. 2016. 'Measuring Financial Capability - Identifying the Building Blocks' Money Advice Service, November 2016, London. 
Money Advice Service. 2013. 'The Financial Capability of the UK' Report. London: Money Advice Service,

Mundy, S. 2011. 'Financial capability: Why is it Important and how can it be Improved? Perspective Report' CFBT Education Trust.

Neymotin, F. 2010. 'Linking Self-Esteem with the Tendency to Engage in Financial Planning' Journal of Economic Psychology 31 (6): 996-1007.

OECD INFE. 2011. Measuring Financial Literacy: Core Questionnaire in Measuring Financial Literacy: Questionnaire and Guidance Notes for conducting an Internationally Comparable Survey of Financial literacy, Organization for Economic Co-Operation and Development (Paris).

OECD INFE Policy Guidance. 2018. Digitalisation and Financial Literacy. http://www.oecd.org/finance/G20-OECD-INFE-Policy-Guidance-Digitalisation-FinancialLiteracy-2018.pdf

Office for National Statistics. 2017. 'Labour Force Survey' 2017. https://www.ons.gov.uk/businessindustryandtrade/itandinternetindustry/bulletins/internetu sers/2017

O'Reilly, G. A. and D. Spruijt-Metz. 2013. 'Current Mhealth Technologies for Physical Activity Assessment and Promotion' American Journal of Preventative Medicine 45 (4): 501-07.

Parker, A. M., W. B. Bruin, J. Yoong and R. Willis 2012. 'Inappropriate Confidence and Retirement Planning: Four Studies with a National Sample' Journal of Behavioral Decision Making, 25: 382-389

Peiris, D., Miranda, J. J. and D. Mohr. 2018. 'Going Beyond Killer Apps: Building a Better Mhealth Evidence Base' BMJ Global Health 3: 1-3.

Peng, W., Kanthawla, S., Yuan, S. and S. Hussain. 2016. 'A Qualitative Study of User Perceptions of Mobile Health Apps' BMC Public Health 16: 1-11.

Piercy, L. 2018. 'Changing Behaviour around Online Transactions' https://www.fincap.org.uk/document/WqgSUSoAACoA4gIR/changing-behaviour-aroundonline-transactions

Puri, M., and D. T. Robinson. 2007. 'Optimism and Economic Choice' Journal of Financial Economics, 86 (1): 71-99.

Reedy, K., and R. Goodfellow. 2012. 'Digital and Information Literacy Framework' Open University

November 2012.

Schoeppe, S., S. Alley, W. Van Lippevelde, N. Bray, S. Williams, M. Duncan and C. Vandelanotte. 2016. 'Efficacy of Interventions that use Apps to Improve Diet, Physical Activity and Sedentary 
Behaviour: A Systematic Review' International Journal of Behavioral Nutrition and Physical Activity 13: 1-26.

Servon, L.J, and R. Kaestner. 2008. 'Consumer Financial Literacy and the Impact of Online Banking on the Financial Behavior of Lower-Income Bank Customers" The Journal of Consumer Affairs 42 (2): 271-305.

Shephard, D., J. M., Contreras, J. Mueris, A. te Kaat, S. Bailey, A. Custers, and N. Spencer. 2017. Beyond Financial Literacy: The Psychological Dimensions of Financial Capability' (Technical Report). Think Forward Initiative.

http://www.thinkforwardinitiative.com/research/the-psychological-dimensions-offinancialcapability

Smith, J.J., P. J. Morgan, R. C. Plotnikoff, K. A. Dally, J. Salmon, A. D. Okely, T. L. Finn and D.R. Lubans. 2014. 'Smart-Phone Obesity Prevention Trial for Adolescent Boys in Low-Income Communities: The ATLAS RCT'. Pediatrics 134 (3): 723-31.

Spencer, N., J. Nieboer, and A. Elliott. 2015. Wired for Imprudence. London: RSA

Spires, H. and M., Bartlett. 2012. 'Digital literacies and learning: Designing a Path Forward' Friday Institute White Paper Series. NC State University.

Taylor, M. 2011. 'Measuring Financial Capability and its Determinants Using Survey Data' Social Indicators Research 102 (2): 297-314.

UK Finance. 2018. 'The Way We Bank Now' https://www.ukfinance.org.uk/wpcontent/uploads/2018/05/WWBN-FINAL-Digital.pdf

Van Rooij, M., A. Lusardi and R. Alessie. 2011. 'Financial Literacy and Stock Market Participation' Journal of Financial Economics 101 (2): 449-472.

Van Rooij, M., A. Lusardi and R. Alessie. 2012. 'Financial Literacy, Retirement Planning, and Households Wealth' Economic Journal, 122: 449-478

Von Stumm, S., M. F. O'Creevy and A. Furnham. 2013. 'Financial Capability, Money Attitudes and Socioeconomic Status: Risks for Experiencing Adverse Financial Events' Personality and Individual Differences 54 (3): 344-349.

Watts, S., A. Mackenzie, C. Thomas, A. Griskaitis, L. Mewton, A. Williams and G. Andrews. 2013. 'CBT for Depression: A Pilot RCT Comparing Mobile Phone Vs. Computer' BMC Psychiatry 13 (1): 1-9.

World Bank. 2015. 'World Development Report 2015: Mind, Society and Behaviour' Washington, DC: World Bank. 


\section{Tables and Figures}

Table 4.1 Post-intervention response

\begin{tabular}{lcccc}
\hline & \multicolumn{2}{c}{ Treatment } & Control \\
\cline { 2 - 4 } & \multicolumn{2}{c}{ Downloaded app } & Total & \\
\hline Pes & 176 & No & & \\
\hline Pre-intervention survey & 147 & 64 & 240 & 260 \\
Post-intervention survey & $84 \%$ & 44 & 191 & 212 \\
Response & & $69 \%$ & $80 \%$ & $82 \%$ \\
\hline
\end{tabular}

Table 5.1 Comparison of treatment and control group for known confounders

\begin{tabular}{lrrr}
\hline Variable & Control & Treatment & p-value \\
\hline Female & 0.76 & 0.77 & 0.715 \\
Partner & 0.47 & 0.54 & 0.147 \\
Employed & 0.43 & 0.46 & 0.589 \\
Retired & 0.08 & 0.06 & 0.501 \\
Education $^{+}$ & 0.60 & 0.64 & 0.354 \\
Age $^{+}$ & 39.6 & 40.4 & 0.547 \\
Children $^{+}$ & 1.0 & 1.0 & 0.919 \\
\hline
\end{tabular}

Notes: ${ }^{\dagger}$ t-tests of equality of means ${ }^{\ddagger}$ Chi-square test of independence. All other statistical tests of differences are tests on the equality of proportions. Female Proportion of female respondents Partner Proportion of respondents with partner Employed Proportion of respondents employed Retired Proportion of respondents retired Education Highest educational qualification obtained A-level or above Age Respondent age Children Number of children living in household. $p<0.10 * p<0.05 * * p<0.01 * * *$. 
Table 5.2 Estimates of treatment effect for financial knowledge, understanding and basic skills

\begin{tabular}{llllll}
\hline & & \multicolumn{2}{c}{ ITT } & \multicolumn{2}{c}{ CACE } \\
\cline { 3 - 5 } Theme & Variable & Coeff. & (s.e.) & Coeff. & $($ s.e. $)$ \\
\hline Self-confidence & Loan confidence & $0.095^{* *}$ & 0.047 & $0.172^{* *}$ & 0.086 \\
Financial literacy & Financial literacy & $0.110^{* * *}$ & 0.042 & $0.199^{* *}$ & 0.078 \\
Digital literacy & Buying online & 0.011 & 0.026 & 0.021 & 0.047 \\
Digital literacy & Paying bills online & 0.006 & 0.028 & 0.011 & 0.051 \\
Digital literacy & Bank online & 0.045 & 0.029 & 0.081 & 0.052 \\
Digital literacy & Online comparisons & 0.052 & 0.045 & 0.096 & 0.081 \\
Digital literacy & Buying online improved & -0.048 & 0.050 & -0.087 & 0.091 \\
Digital literacy & Paying bills online improved & -0.035 & 0.050 & -0.064 & 0.091 \\
Digital literacy & Bank online improved & -0.011 & 0.050 & -0.020 & 0.091 \\
Digital literacy & Online comparisons improved & -0.008 & 0.050 & -0.013 & 0.091 \\
\hline
\end{tabular}

Notes: ITT - OLS regressions. CACE - 2SLS regression. Loan confidence 'When you are shown information about a financial product such as a loan, credit card or store card, how confident are you that you understand the total amount you need to repay?' $\left(0={ }^{\prime} 1\right.$. Not confident-3', $1=$ ' 4 5. Very confident'). Financial literacy Three or more correct out of four financial literacy questions Buying online 'How would you rate your ability when using the internet for ...buying a product online?' ( $0==^{\prime}$ Fair', 'Poor', 'Bad' $1=$ 'Excellent', 'Good') Paying bills online '...for paying bills' (0='Fair', 'Poor', 'Bad' 1= 'Excellent', 'Good') Bank online '...using your bank's online services?' (0='Fair', 'Poor', 'Bad' 1= 'Excellent', 'Good') Online comparisons '...comparing financial products and services?' (0='Fair', 'Poor', 'Bad' 1= 'Excellent', 'Good'). Buying online improved 'Over the last 6 months, has your ability to use the internet for the following purposes improved? ....buying a product online?' ('Yes'/'No') Paying bills online improved '...for paying bills' ('Yes'/'No') Bank online improved '...........using your bank's online services?' (('Yes'/'No') Online comparisons improved '............Comparing financial products and services?' ('Yes'/'No'). $p<0.10 * p<0.05 * * p<0.01 * * *$. 
Table 5.3 Estimates of treatment effect for attitudes and motivations

\begin{tabular}{llllll}
\hline & & \multicolumn{2}{c}{ ITT } & \multicolumn{2}{c}{ CACE } \\
\cline { 3 - 5 } Theme & Variable & Coeff. & (s.e.) & Coeff. & (s.e.) \\
\hline Attitudes to future & Time discounting & 0.009 & 0.043 & 0.017 & 0.078 \\
Attitudes to future & Live for today & $0.106^{* *}$ & 0.049 & $0.193^{* *}$ & 0.089 \\
Attitudes to future & Hate borrowing & $-0.103^{* *}$ & 0.042 & $-0.188^{* *}$ & 0.077 \\
Attitudes to future & Save for rainy day & 0.008 & 0.024 & 0.015 & 0.044 \\
Attitudes to future & Save for retirement & 0.041 & 0.045 & 0.074 & 0.081 \\
Attitudes to future & Buy on impulse & -0.060 & 0.344 & -0.110 & 0.623 \\
Attitudes to future & Shop around & 0.004 & 0.024 & 0.007 & 0.043 \\
Ability to effect change & Self-efficacy & $0.086^{* *}$ & 0.042 & $0.156^{* *}$ & 0.077 \\
Ability to effect change & Anxiety about finances & 0.013 & 0.050 & 0.023 & 0.091 \\
Ability to effect change & Keeping track of finances & $0.041^{* *}$ & 0.019 & $0.074^{* *}$ & 0.034 \\
Ability to effect change & Money management confidence & -0.145 & 0.186 & -0.264 & 0.338 \\
Ability to effect change & Seek advice & 0.014 & 0.035 & 0.025 & 0.063 \\
Ability to effect change & Happy to use tech & $0.111^{* * *}$ & 0.041 & $0.201^{* * *}$ & 0.075 \\
Consumption influences & Spend like friends & -0.004 & 0.263 & -0.008 & 0.476 \\
Consumption influences & Spend on children & 0.405 & 0.390 & 0.737 & 0.710 \\
Resilience & Bounce back & 0.006 & 0.034 & 0.011 & 0.062 \\
Resilience & Surviving stressful events & -0.018 & 0.048 & -0.033 & 0.087 \\
Resilience & Recovering from stressful events & 0.068 & 0.046 & 0.123 & 0.083 \\
Resilience & Snapping back & -0.026 & 0.047 & -0.046 & 0.085 \\
Resilience & Coming through difficulties & 0.049 & 0.046 & 0.088 & 0.083 \\
Resilience & Getting over setbacks & 0.001 & 0.042 & 0.001 & 0.076 \\
\hline
\end{tabular}

Notes: ITT - OLS regressions. CACE - 2SLS regression. Time discounting Would take $£ 400$ in two months and not $\mathrm{f} 200$ now. Live for today 'When it comes to money I prefer to live for today rather than plan for tomorrow' ('Strongly disagree', 'Disagree'). Hate borrowing 'I hate to borrow - I would much rather save up in advance' ('Strongly agree', 'Agree'). Save for rainy day 'How important, if at all, do you think it is to save money for a rainy day '('Very important', 'Fairly important'). Save for retirement 'How important, if at all, do you think it is to put aside money for your retirement' ('Very important', 'Fairly important'). Buy on impulse 'I often buy things on impulse' (0-10) Shop around 'How important, if at all, do you think it is shop around in order to make your money go further' ('Very important', 'Fairly important'). Self-efficacy 'Nothing I will do will make much difference to my financial situation' ('Strongly disagree', 'Disagree'). Anxiety about finances 'Thinking about my financial situation makes me anxious' ('Strongly disagree', 'Disagree'). Keep track of finances 'How important, if at all, do you think it is to keep track of your and your partner/spouse's income and expenditure' ('Very important', 'Fairly important'). Money management confidence 'How confident do you feel managing your money?' (0-10). Seek advice If in financial difficulty 'Seek advice from family and friends ' or 'Seek advice from a money advice service'. Happy to use tech 'I would be happy to use technology to help me in my day to day financial decision making' ('Strongly agree', 'Agree'). Spend like friends 'I feel under pressure to spend like my friends even when I can't afford it' (0-10). Spend on children 'I feel under pressure to spend money on my children even when I can't afford it.' (0-10). Bounce back 'I tend to bounce back quickly after hard times' ('Strongly agree', 'Agree'). Surviving stressful events 'I have a hard time making it through stressful events' ('Strongly disagree', 'Disagree'). Recovering from stressful events 'It does not take me long to recover from a stressful event' ('Strongly agree', 'Agree'). Snapping back, 'It is hard for me to snap back when something bad happens ('Strongly disagree', 'Disagree'). Coming through difficulties 'I usually come through difficult times with little trouble ('Strongly agree', 'Agree'). Getting over setbacks 'I tend to take a long time to get over set-backs in my life' ('Strongly disagree', 'Disagree'). $p<0.10^{*} p<0.05^{* *} p<0.01 * * *$ 


\begin{tabular}{llllll}
\hline & & \multicolumn{2}{c}{ ITT } & \multicolumn{2}{c}{ CACE } \\
\cline { 2 - 5 } Theme & Variable & Coeff. & (s.e.) & Coeff. & $($ s.e. $)$ \\
\hline Managing bill payment & Unexpected expense & $0.121^{* * *}$ & 0.046 & $0.221^{* * *}$ & 0.084 \\
Keeping track & Check account & $0.062^{*}$ & 0.033 & $0.113^{*}$ & 0.060 \\
Keeping track & Know balance & -0.038 & 0.047 & -0.069 & 0.086 \\
Keeping track & Tracking finances & 0.002 & 0.026 & 0.003 & 0.048 \\
Keeping track & Keeping track & 0.022 & 0.042 & 0.040 & 0.077 \\
Keeping track & Personal budget & 0.030 & 0.051 & 0.054 & 0.093 \\
Maximising income & Get deal on financial products & 0.022 & 0.045 & 0.040 & 0.082 \\
Maximising income & Get deal on utilities & -0.017 & 0.050 & -0.032 & 0.091 \\
Maximising income & Get other deal & 0.022 & 0.050 & 0.040 & 0.090 \\
Build resilience & Save monthly & 0.012 & 0.039 & 0.023 & 0.070 \\
\hline
\end{tabular}

Notes: ITT - OLS regressions. CACE - 2SLS regression. Unexpected expense Pay an unexpected bill of $£ 300$ with own money, dipping into savings or cutting back on essentials. Check account Check how much money in current account 'every day' or 'at least once a week'. Know balance Know balance on current account 'within a pound or two' or 'within 110 '. Tracking finances 'Do you keep track of your personal income and expenditure?' (Y/N). Keeping track Regularly check incomings and outgoings. Personal budget 'Do you set a personal budget of how much you spend?' (Y/N). Get deal on financial products '. 'In the last 6 months, have you tried to get a better deal on.....financial products (for example: current account/ credit union account, credit card, savings account, home buildings/ content insurance)' (Y/N). Get deal on utilities '.... Household utilities (for example: gas, electricity)' (Y/N). Get other deal '...other (for example mobile, internet)'. Save monthly 'Do you currently save some money each month?' (Y/N). $p<0.10^{*} p<0.05 * * p<0.01 * * *$ 
Table 5.5 Estimates of treatment effect on financial wellbeing

\begin{tabular}{llllc}
\hline \multirow{2}{*}{ Variable } & \multicolumn{3}{c}{ ITT } & \multicolumn{2}{c}{ CACE } \\
\cline { 2 - 5 } & Coeff. & (s.e.) & Coeff. & $($ s.e. $)$ \\
\hline Financial satisfaction & 0.041 & 0.205 & 0.075 & 0.372 \\
Debt trouble & -0.023 & 0.027 & -0.042 & 0.048 \\
Money over & 0.014 & 0.050 & 0.026 & 0.091 \\
Managing financially & -0.038 & 0.041 & -0.069 & 0.075 \\
Bills and credit burden & -0.037 & 0.050 & -0.068 & 0.091 \\
Bills and credit arrears & 0.006 & 0.028 & 0.011 & 0.051 \\
Tracking approach works & -0.217 & 0.157 & -0.394 & 0.284 \\
Keeping up with bills & 0.023 & 0.032 & 0.041 & 0.058 \\
Food security & $-0.074^{*}$ & 0.042 & $-0.135^{*}$ & 0.077 \\
Total owed & 0.372 & 0.295 & 0.682 & 0.532 \\
\hline
\end{tabular}

Notes: ITT - OLS regressions. CACE - 2SLS regression. Financial satisfaction 'How satisfied are you with your overall financial circumstances?' (1-10). Debt trouble Trouble with debts 'only sometimes' or 'never'. Money over Money over at the end of the week/month? 'Always', 'Most weeks/months' or 'More often than not'. Managing financially 'Manage very well' or 'Manage quite well'. Bills and credit burden Keeping up with your bills and credit commitments is 'not a burden at all'. Bills and credit arrears 'In the last 6 months, have you fallen behind on, or missed any payments for credit commitments or domestic bills for 3 or more months?' ('No'=1). Tracking approach works ' Thinking overall about yours and your partner/spouse's approach to keeping track of income and expenditure, how well do you think this approach works?' (0-10). Keeping up with bills Keeping up with your bills and credit commitments 'without any difficulties' or 'Keeping up but it is a struggle from time to time'. 'Food security ' Always had enough of the kinds of food you wanted to eat'. Total owed Sum of balances on credit cards, store cards, personal loans, hire purchase, car finance and student loans. $p<0.10 * p<0.05 * * p<0.01 * * *$ 


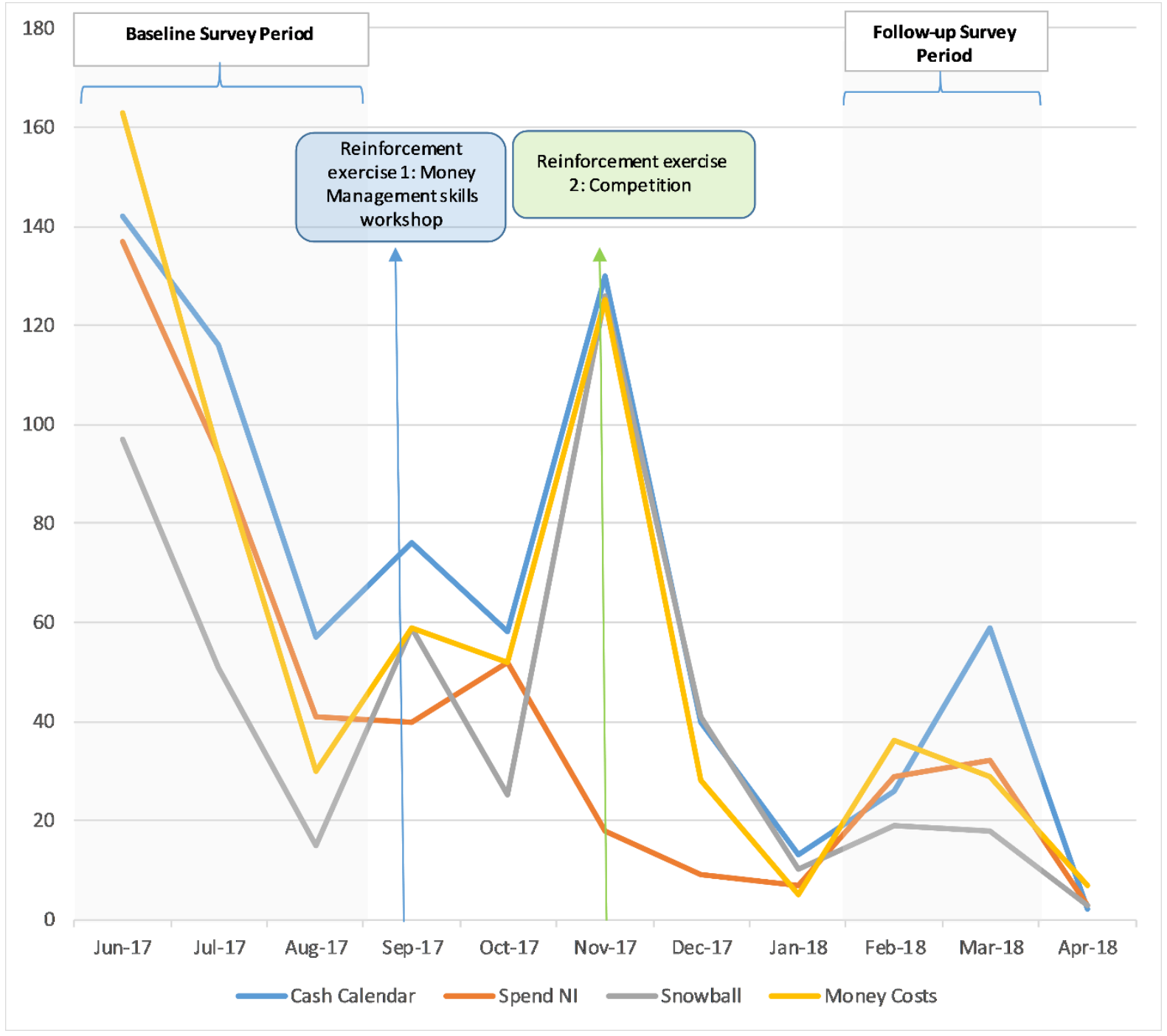

